\title{
AGENDAS, PREFERÊNCIAS, COMPETIÇÃO: PT e PSDB em disputas presidenciais ${ }^{1}$
}

\author{
Rafael Madeira * \\ Soraia Vieira* * \\ Gabriela Tarouco ** *
}

\begin{abstract}
Há um debate na ciência política brasileira sobre a bipolarização do sistema partidário, decorrente da concentração da competição, nas eleições presidenciais, em dois partidos: PT e PSDB. O objetivo do artigo é identificar o conteúdo e os termos da competição entre tais partidos no que se refere às suas ênfases temáticas, através da comparação entre os programas de governo de cada um para as eleições presidenciais de 2006 a 2014. A hipótese, derivada da saliency theory, é de que a competição entre eles se baseia na seleção de temas específicos e agendas alternativas. O método utilizado para mensuração das agendas e preferências é a análise de conteúdo, com aplicação das categorias do Manifest Research Group/MARPOR. Os resultados revelam que as plataformas se aproximam por conterem os temas da agenda pública nacional, mas se distinguem nas prioridades que estabelecem e na direção em que adaptam suas ênfases ao longo do tempo.

Palavras-chave: Manifestos. Análise de conteúdo. Partidos políticos. Eleições presidenciais. Agenda de políticas públicas.
\end{abstract}

\section{INTRODUÇÃO}

A polarização da competição presidencial no Brasil vem sendo observada há vários ciclos eleitorais e amplamente discutida na literatura especializada (Limongi; Cortez 2010; Melo; Camara, 2012). Entretanto, ainda não temos uma boa medida do conteúdo dessa competição polarizada. Estariam o Partido dos Trabalhadores (PT) e o Partido da Social Democracia Brasileira (PSDB), ao dividirem os eleitores, oferecendo-lhes alternativas realmente distintas em termos de plataformas para o governo federal?

* Pontifícia Universidade Católica do Rio Grande do Sul (PUCRS). Programa PósGraduação em Ciências Sociais. Avenida Ipiranga, 6681. Cep: 90.619-900. Partenon - Porto Alegre - Rio Grande do Sul-Brasil. rafaelmachadomadeira@gmail.com

** Universidade Federal Fuminense.

Avenida do Trabalhador, 179. Cep: 23914-360. Jacuecanga - Angra dos Reis - Brasil. soraiamv@id.uff.br

${ }^{* * *}$ Universidade Federal de Pernambuco.

Rua Acadêmico Hélio Ramos, s/n - $14^{\circ}$ andar, Cidade Universitária Cep: 50.670-901. Recife - Pernambuco - Brasil. gabrielat@uol.com.br

${ }^{1}$ Versões preliminares deste trabalho foram apresentadas no $37^{\circ}$ Encontro da ANPOCS em 2013, no Congresso da IPSA em 2014 e no $8^{\circ}$ Congresso do CEISAL em 2016. Agradecemos aos participantes pelos comentários e sugestões e aos pareceristas do Caderno CRH pelas valiosas críticas e recomendações.
Enquanto similitudes na origem sugerem que ambos os partidos teriam agendas semelhantes, eles não ocupam a mesma posição na escala ideológica (Tarouco; Madeira, 2015). Além disso, se a configuração bipartidária na competição presidencial seria um incentivo para que os dois partidos se identificassem em busca do voto do eleitor mediano, ao mesmo tempo, PT e PSDB têm incentivos contrários, vindos da esfera estadual da competição, onde se espera que a configuração mais fragmentada e os contextos locais específicos limitem a estratégia de mobilidade e ampliação do apelo eleitoral.

Historicamente, o PT e o PSDB se originaram no campo da esquerda do espectro político. Embora, em seu momento originário, tenham apresentado ideias alinhadas, algumas importantes diferenças marcam a trajetória desses partidos. O PT surgiu durante a reforma partidária de 1979 e foi considerado pelos analistas políticos como o único partido brasileiro identificado com as massas (Kinzo, 1993; Samuels, 1997), enquanto o PSDB surgiu em 1987, durante os trabalhos da Assembleia Nacional Constituinte, a partir de uma cisão no PMDB e em outros partidos, configurando o que Duver- 
ger (1980) considera um partido de quadros.

Embora tenham surgido em momentos diferentes e com distintas composições, o PT e o proto-PSDB ${ }^{2}$ comportaram-se de maneira semelhante durante as votações da Assembleia Nacional Constituinte (Power, 2003). Não obstante, os posicionamentos desses partidos se afastam a partir de 1993, quando o PSDB ingressa na coalizão governista, e a polarização se acirra a partir de 1994, momento em que a coalizão do partido assume o Executivo Federal (Power; Zucco, 2009).

PT e PSDB firmaram-se como os dois maiores partidos a competir não somente pelo Executivo Federal, mas também com claros impactos nos demais âmbitos da federação (governos estaduais e municipais). Essa clivagem tem exercido um relevante papel como agente estruturante da disputa à Presidência da República nas últimas duas décadas (Borges; Lloyd, 2016; Limongi ,Cortez, 2010; Melo; Camara, 2012; Samuels; Zucco, 2014). ${ }^{3}$

Neste trabalho são analisados os programas de PT e PSDB a fim de buscar suas preferências sobre as agendas de políticas públicas. O foco desta investigação é constituído dos programas de governo lançados por esses partidos de 2006 a 2014, quando tiveram como candidatos: em 2006, Geraldo Alckmin (PSDB) キ e Luis Inácio Lula da Silva (PT); em 2010, José Serra (PSDB) e Dilma Rousseff (PT); e, em 2014, A Ácio Neves (PSDB) e Dilma Rousseff (PT).

Os programas apresentados, tanto o partidário como o de governo, são uma ferramenta muito importante para a análise do posicionamento e do comportamento de um partido $\therefore$ político. Neles estão expressas as preferências

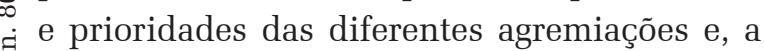
§ं partir da análise desses documentos, é possível $\vec{s}$ estimar o posicionamento de um partido, sua evolução ao longo do tempo e seu comportamento em comparação com o de seus concor-

2 Timothy Power analisou a votação dos legisladores que formaram o PSDB, grupo que denominou Proto-PSDB.

${ }^{3}$ Além desses autores, Carreirão (2014) e Melo (2015) levantam argumentos importantes para se problematizar o impacto desta polarização. rentes. Apesar da importância desse tipo de documento, existem poucas análises focadas nos manifestos partidários, especialmente quando se trata de partidos brasileiros e latino-americanos. Para empreender essa análise, é adotado o método de análise de conteúdo de textos políticos, cujos detalhes são discutidos no tópico um deste artigo.

O texto está organizado em quatro partes, além desta introdução. No item um, são discutidos os pressupostos metodológicos e teóricos que orientam a pesquisa. No tópico dois, são analisadas as agendas que podem ser identificadas nos programas de governo dos dois partidos em questão (PT e PSDB) em termos de ênfases programáticas. O foco da terceira parte são as dimensões da competição política encontradas nos programas, com destaque para a dimensão pós-materialista. $\mathrm{O}$ artigo termina com um resumo dos resultados e as conclusões dos autores.

\section{A ABORDAGEM DAS ÊNFASES PROGRAMÁTICAS E A TÉCNICA DE ANÁLISE DE CONTEÚDO}

Para esta investigação, é utilizado o método de análise de conteúdo, a partir da abordagem do Manifesto Research Group - MRG. ${ }^{4}$ Essa técnica consiste em quantificar as unidades de texto dedicadas a cada assunto. Os programas foram segmentados em frases e cada uma delas foi classificada em uma das categorias elaboradas pelo MRG. ${ }^{5}$

As bases teóricas que guiam a análise dos manifestos realizada pelo MRG-MARPOR encontram-se em Robertson (1976), que as desenvolve a partir da problematização de alguns

${ }^{4}$ O MRG é um projeto de cooperação lançado em 1979, inicialmente abrigado no Consorcio Europeu para Investigação Política (ECPR). A partir de 1989, passou a sediar-se em Berlim, sob o nome de CMP - Comparative Manifestos Project e, a partir de 2009, foi sucedido pelo MARPOR - Manifesto Research in Political Representation (Volkens et al., 2013).

${ }^{5}$ Acrescentamos à lista do MRG a categoria 306 - Instituições do Sistema Político -, para contemplar as referências a temas relacionados a esse assunto, encontradas nos documentos analisados. 
dos pressupostos do modelo downsiano de competição eleitoral. O autor de A theory of party competition sustenta, por exemplo, que partidos e candidatos não teriam tanta liberdade para definir o discurso eleitoral a seu bel prazer.

Entretanto, a formulação de tal discurso seria perpassada por uma série de condicionantes, dois dos quais fundamentais para abordar a saliency theory - aspecto central na análise dos manifestos:

Partidos disputam votos ou eleições em diferentes arenas. Não raro, circunscrições eleitorais diferentes possuem características socioeconômicas e culturais diferentes, o que reduz a probabilidade de candidatos de um mesmo partido utilizarem o mesmo discurso eleitoral (Robertson, 1976, p. 34).

Em circunscrições não tão receptivas ao discurso de um determinado partido político, seu candidato é tensionado a adotar uma fala que o distingue dos demais concorrentes, ou do discurso nacional do partido. No entanto, a estratégia para se diferenciar não é a de adotar posicionamentos contrários aos do partido nas questões mais delicadas a serem defendidas em âmbito local, mas sim a de tratar de temas e posicionamentos defendidos pelo partido em outras áreas, evitando os temas mais sensíveis nos distritos (Robertson, 1976, p. 146).

\begin{abstract}
A menos que se esteja inaugurando um regime democrático, a disputa eleitoral está fortemente relacionada ao desempenho dos partidos em governos anteriores. A competição eleitoral se dá, necessariamente, entre um partido que é governo e busca permanecer como tal e partido(s) de oposição. A escolha dos temas a serem abordados pelos diferentes candidatos para interpretar o desempenho do partido incumbent estará diretamente vinculada à posição desses candidatos em relação ao governo que se encerra e à avaliação do eleitorado sobre o desempenho do governo em diferentes áreas. Candidatos de oposição irão ressaltar temas nos quais o governo não tem popularidade, enquanto o candidato do partido do governo buscará ressaltar áreas em que o governo tem bons índices de aprovação (Robertson, 1976, p. 127).
\end{abstract}

Nesse cenário, quando o governo possui altos índices de aprovação, as candidatu- ras oposicionistas enfrentam o difícil desafio de identificar seus pontos mais vulneráveis e propor soluções (políticas públicas) compatíveis com seu histórico quando no governo. Por outro lado, quando o governo é mal avaliado, cabe ao candidato governista a difícil tarefa de identificar e defender eventuais pontos fortes do governo e justificar o fraco desempenho nas demais áreas.

Esta perspectiva permite analisar o discurso eleitoral dos partidos a partir da confluência de uma teia de fatores em que se articulam elementos sincrônicos - como o contexto eleitoral (avaliação do governo) e a estratégia eleitoral (quais temas, issues, cada candidatura utilizará para buscar pautar a agenda eleitoral) - e elementos diacrônicos, como a atuação do partido (como governo e como oposição) em mandatos anteriores.

A metodologia aqui empregada na análise de conteúdo dos programas possui dois momentos que são cruciais no que tange ao tratamento dos dados:

1. a divisão dos textos em sentenças e quase sentenças; e

2. a atribuição a cada sentença de uma das categorias utilizadas para a classificação. As implicações relacionadas à realização dessas tarefas por codificadores treinados e (ou) por programas de computador sobre o grau de confiabilidade e validade dos dados é tema fundamental na atual agenda que envolve essa perspectiva metodológica, e é tema de extensa bibliografia no âmbito do MRG (ver nota quatro).

Benoit, Laver e Mikhaylov (2008), por exemplo, salientam o fato de que os programas analisados pelo atual MARPOR são, via de regra, classificados por um codificador e apenas uma vez. Para aumentar a confiabilidade dos dados examinados, adotamos, neste trabalho, as seguintes estratégias: cada programa foi fracionado por um dos três pesquisadores, e a segmentação resultante foi revisada (em um segundo momento) por outro, sendo que as dúvidas foram debatidas caso a caso, tendo o 
terceiro pesquisador como "fiel da balança"; no que tange à classificação, os seis programas foram classificados por cada um dos três pesquisadores, e a classificação adotada como parâmetro é o resultado da comparação dessas três classificações.

A opção pela codificação manual implica a necessidade de testar a sua confiabilidade. A confiabilidade de uma medida é a sua qualidade de estar isenta de erros de mensuração e pode ser avaliada comparando-se resultados obtidos por codificadores diferentes.

A análise de conteúdo que fundamenta este trabalho teve sua confiabilidade testada através da comparação entre as codificações feitas por cada um dos três autores. Os resultados foram bem semelhantes, entretanto, a mera associação entre eles (medida por testes de qui-quadrado, por exemplo) não seria suficiente para afirmar a confiabilidade, pois, mesmo entre variáveis sem qualquer relação entre si, é razoável esperar alguma coincidência aleatória. ${ }^{6}$

$\mathrm{O}$ teste que distingue a coincidência substantiva entre duas classificações daquela que seria esperada por aleatoriedade entre classificações independentes é o índice kappa, ou simplesmente índice $k$, proposto por Jacob Cohen (1960). Trata-se de um coeficiente de concordância para escalas nominais que remoA ve o efeito de coincidências aleatórias, ou seja, ๖ั que mede o grau em que duas ou mais classificações concordam substantivamente entre si, para além das coincidências que seriam produzidas pelo acaso, na hipótese (nula) de total

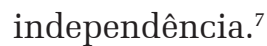

$O$ índice $k$ varia de -1 (quando todas as classificações divergem) a 1 (quando todas as classificações são idênticas) e equivale a 0 . ${ }^{6}$ Além disso, esse tipo de teste conta como associação não - apenas as concordâncias, mas também as discordâncias sistemáticas entre duas variáveis: frases em que um pesquisador usasse sistematicamente uma categoria e outro $\geq$ pesquisador utilizasse outra categoria diferente são casos ๙ de discordância que indicam problema de confiabilidade, T. mesmo contribuindo para o cálculo da associação entre as duas medidas.

${ }^{7} \mathrm{O}$ cálculo do índice $\mathrm{k}$ é o seguinte: $\mathrm{k}=$ (no de concordâncias observadas - no de concordâncias aleatórias esperadas) / (Número total - no de concordâncias aleatórias esperadas) quando a proporção de concordâncias se limita à proporção de coincidências aleatórias.

Como pode ser visto na Tabela 1, dois dos valores encontrados estão na faixa considerada "boa" pela literatura, e um deles atingiu um valor considerado excelente (Bonnardel, 2001; Landis; Koch, 1977), ${ }^{8}$ o que nos permitiria adotar qualquer uma das três classificações. As análises deste artigo, assim, estão baseadas na codificação do pesquisador 3.

Tabela 1 - Índice $K$ de concordância entre as classificações dos pesquisadores

\begin{tabular}{l|l}
\hline Par de classificações & Índice K \\
\hline Pesquisador 3 x Pesquisador 2 & 0,883653721 \\
\hline Pesquisador $3 \times$ Pesquisador 1 & 0,684275116 \\
\hline Pesquisador 1x Pesquisador 2 & 0,664122137 \\
\hline Fonte:
\end{tabular}

\section{ÊNFASES E AGENDAS NOS PROGRAMAS DE GOVERNO DAS COLIGAÇÕES DO PT E DO PSDB}

Este artigo busca responder à seguinte pergunta: o que os programas de governo das coligações $^{9}$ encabeçadas pelo PT e pelo PSDB nos dizem sobre as duas agendas de políticas públicas que têm concentrado a competição presidencial no Brasil nos últimos quase 20 anos? A fim de responder a essa questão, são utilizados como base para a análise os programas de governo do PT e do PSDB nas três últimas eleições presidenciais brasileiras.

Cabe destacar que os programas de governo e os programas partidários apresentam algumas diferenças importantes. Os primeiros são elaborados em uma conjuntura específica

${ }^{8}$ Excelente: $>$ ou $=0,81$; Bom: 0,80 - 0,61; Moderado: 0,60 - 0,41; Medíocre: 0,40 - 0,21; Fraca:

0,20 - 0,0; Muito fraca: $<0,0$.

${ }^{9}$ Referimo-nos às coligações, variáveis que, ao longo do período, têm abrigado as candidaturas do PT e do PSDB. As preferências e as agendas dos partidos que encabeçam as chapas foram objeto de outras análises (Tarouco, 2011; Vieira, 2016). Neste artigo, tratamos os programas de governo das coligações como proxies das preferências e agendas, em termos de plataformas de governo endossadas, dos partidos que as lideram. 
e não refletem somente o posicionamento do partido, mas da coalizão eleitoral que apoia o candidato. ${ }^{10}$ Em geral, os objetivos apresentados por esses documentos são de curta duração e estão relacionados ao governo da referida coalizão. Por outro lado, os programas partidários referem-se exclusivamente ao partido e têm duração maior. Os programas utilizados neste trabalho foram coletados nas páginas eletrônicas dos partidos, como é apresentado no Quadro 1.

Da leitura de tais documentos emergem, numa análise inicial, algumas regularidades interessantes. Principalmente nas duas primeiras eleições, os programas do PT são mais curtos e os do PSDB mais extensos. O programa de Alckmin tem 170 páginas, o de Serra, 280 e o de Aécio, 69, enquanto os de Lula e Dilma chegam apenas a 34,11 e 42, respectiva- mente. Os programas de governo anteriores do PSDB (FHC I e FHC II) também foram bastante extensos, com cerca de 300 páginas cada um, tendo inclusive sido publicados no formato de livros. Os programas de governo anteriores do PT, por outro lado, sempre foram menores (234 páginas em 1994 e 70 em 1998).

Outro aspecto que merece destaque é a inclusão, no programa do PSDB de 2010, de propostas recebidas de internautas. Esse procedimento é anunciado na página do partido, que apresenta o documento como resultado da colaboração da população. Isso é reiterado no próprio documento, no qual os tópicos provenientes de sugestões externas aparecem sinalizados com emoticons. Tratava-se, naquele momento, de uma estratégia inovadora de campanha eleitoral, com o uso de canais alternativos às mídias tradicionais e a incorporação

Quadro 1 - Documentos analisados

\begin{tabular}{|c|c|c|c|}
\hline Eleição & Documento & Coligação & Fonte \\
\hline 2006 & $\begin{array}{l}\text { Programa de Governo Geraldo } \\
\text { Alckmin } 45 \text { Presidente }\end{array}$ & $\begin{array}{l}\text { Por um Brasil Decente (PSDB, } \\
\text { PFL). }\end{array}$ & $\begin{array}{l}\text { http://ww1.psdb.org.br/biblioteca/ } \\
\text { Programa de Governo.pdf, } \\
\text { acessado em } 9 \text { de dezembro 2012, } \\
\text { 16:13. }\end{array}$ \\
\hline 2006 & $\begin{array}{l}\text { Lula de novo com a força do } \\
\text { povo. Lula Presidente - Programa } \\
\text { de Governo } 2007 / 2010\end{array}$ & $\begin{array}{l}\text { A Força do Povo } \\
\text { (PT, PC do B, PRB) }\end{array}$ & 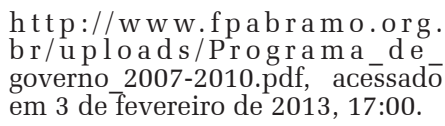 \\
\hline 2010 & $\begin{array}{l}\text { Programa de Governo José } \\
\text { Serra: Uma Agenda para o } \\
\text { Desenvolvimento Sustentável do } \\
\text { Brasil }\end{array}$ & $\begin{array}{l}\text { O Brasil pode mais (PSDB, DEM, } \\
\text { PPS, PTB, PMN, PT do B) }\end{array}$ & $\begin{array}{l}\text { http://www.psdb.org.br/programa- } \\
\text { de-governo-do-candidato-jose- } \\
\text { serra/, acessado em } 7 \text { de dezembro } \\
\text { de } 2012,16: 53 \text {. }\end{array}$ \\
\hline 2010 & $\begin{array}{l}\text { Os } 13 \text { compromissos programá- } \\
\text { ticos de Dilma Rousseff para } \\
\text { debate na sociedade brasileira }\end{array}$ & $\begin{array}{l}\text { Para o Brasil seguir mudando (PT, } \\
\text { PMDB, PC do B, PDT, PRB, PR, } \\
\text { PSB, PSC, PTC, PTN) }\end{array}$ & $\begin{array}{l}\text { www.fpabramo.org.br, acessado } \\
\text { em } 3 \text { de fevereiro de } 2013,17: 10 \text {. }\end{array}$ \\
\hline 2014 & $\begin{array}{l}\text { Diretrizes Gerais - Plano de } \\
\text { Governo - Aécio Neves - PSDB }\end{array}$ & $\begin{array}{l}\text { Muda Brasil (PSDB, PMN, SD, } \\
\text { DEM, PEN, PTN, PTB, PTC, PT } \\
\text { do B) }\end{array}$ & $\begin{array}{l}\text { http://www.psdb.org.br/plano- } \\
\text { d e-go v e r n o - a e c i o - n e v e s - } \\
\text { presidente-2014/, acessado em } 26 \\
\text { de janeiro de } 2015,14: 37 \text {. }\end{array}$ \\
\hline 2014 & $\begin{array}{l}\text { Programa de Governo Dilma } \\
\text { Rousseff - 2014: Mais Mudanças, } \\
\text { Mais Futuro }\end{array}$ & $\begin{array}{l}\text { Com a Força do Povo (PT, PMDB, } \\
\text { PSD, PP, PR, PROS, PDT, PC do } \\
\text { B, PRB) }\end{array}$ & $\begin{array}{l}\text { https://www.pt.org.br/wp-content/ } \\
\text { uploads/2014/07/Prog-de-Governo- } \\
\text { Dilma-2014-INTERNET1.pdf, } \\
\text { acessado em } 12 \text { de abril de 2015, 9:37. }\end{array}$ \\
\hline
\end{tabular}

Fonte: Elaborada pelos autores.

${ }^{10}$ As coligações dos dois partidos aumentaram ao longo do tempo. Tanto PT como PSDB concorreram em 2006 basicamente apenas com seus parceiros tradicionais (PCdoB e PFL, respectivamente) com o único acréscimo do PRB, que abrigava o candidato a vice-presidente na chapa do PT. Nas eleições seguintes, os dois blocos se ampliaram muito, totalizando nove partidos em cada coligação em 2014. Importante chamar a atenção para a heterogeneidade das coalizões: como podemos observar tanto PT quanto PSDB recebem apoio de partidos de diferentes pontos do espectro ideológico.

de novas ferramentas disponíveis via web.

Um último ponto a salientar, com base na leitura dos programas, diz respeito à relevância desse tipo de documento como indicativo das preferências dos partidos. Frequentemente, uma das críticas que a análise de ma- 
nifestos recebe, pelo menos no Brasil, refere-se ao fato de que os eleitores não tomam conhecimento dos documentos programáticos, que são, por isso, vistos como meras formalidades, vazias de conteúdo político autêntico (Miguel, 2010). Quanto a esse ponto, em outros trabalhos, já argumentamos que tais documentos, mesmo ignorados pela grande maioria dos cidadãos, constituem alvos de críticas dos adversários e, por isso, são elaborados com a intenção de tornar público um determinado conjunto de prioridades e ênfases (Tarouco, 2011; Vieira, 2016). Nesta análise, encontramos um indício empírico de que nosso argumento está correto: a presença, no programa do PSDB, de um pequeno trecho remanescente da revisão do texto:

[...] As elevadas taxas de reprovação e de repetência, especialmente nos anos finais do ensino fundamental, continuam existindo. E, dos que conseguem concluir o Ensino Médio, apenas 10\% apresentam um desempenho considerado adequado ao término da educação básica. O melhor é sempre usar educação básica para não atrair a raiva dos sindicatos, é o que está na Constituição. Ensino é considerado linguagem neoliberal com foco no adestramento tecnicista que não se vincula a aprendizagem. (Partido da Social Democracia Brasileira, 2010, p. 85-86, grifo nosso).

Fica evidente, no trecho acima, que o texto do programa foi revisado com o objetiลे vo de torná-lo menos vulnerável a críticas e \& denúncias já esperadas. Provavelmente, esse comentário deveria ter sido removido, mas o "acidente" da edição nos permite insistir  令 tos, sim, para serem lidos e, portanto, têm $\therefore$ um conteúdo que o partido (ou pelo menos

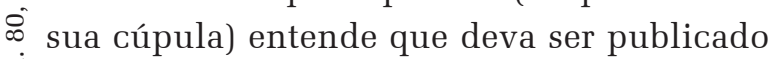
म.

2014, a relevância dos programas de governo no bate eleitoral pôde ser também identificada quando a candidatura ascendente de Marina Silva sofre um considerável desgaste ao se envolver em polêmica sobre a modificação do plano de governo da sua candidatura. identificados. Entretanto, a análise dos documentos, para fins de mensuração e comparação das ênfases programáticas, requer o recurso à técnica de análise de conteúdo, já descrita acima, e cujos resultados, para os programas em análise, neste trabalho, passam a ser discutidos a partir de agora.

O esquema de codificação utilizado é uma adaptação recente da lista de 56 categorias originais do MRG (Alonso; Volkens; Gómez 2012). A adaptação se refere à adição de subcategorias dentro das anteriores, para acolher especificidades dos partidos de vários países, que passam a ser analisados com base nessa abordagem. As categorias de classificação - em que cada frase, de cada programa, foi codificada - são organizadas em um dos sete domínios (além da categoria 000 para frases que não se enquadram em nenhuma categoria): Relações exteriores, Liberdade e democracia, Sistema político, Economia, Bem estar e qualidade de vida, Estrutura da sociedade e Grupos sociais. A Tabela 2 mostra a distribuição do conteúdo dos programas de governo entre domínios da classificação, com os respectivos resíduos ajustados. ${ }^{12}$

Na Tabela 2 os valores em negrito indicam aqueles domínios em que a proporção de texto, em cada programa, se afasta mais significativamente da proporção que seria de se esperar se não houvesse relação entre ênfases e manifestos (ou seja, se os textos dedicassem proporções equivalentes a categorias de todos os domínios, ou proporções aleatórias). No programa do PT de 2006, essa categoria é a 303h (participação do cidadão na gestão pública) e, no de 2010, é a 3057 (competência

${ }^{12}$ Os resíduos correspondem à diferença, em número de desvios padrão, entre o número de frases observado em cada célula (cada combinação de documento e categoria) e o número esperado no caso da hipótese nula de independência, ou seja, na hipótese de que a distribuição das frases fosse igual entre os diferentes programas analisados, ou fosse aleatória. Frequências observadas que se distanciam mais de 1,96 desvios padrão da frequência esperada (na hipótese de independência) têm probabilidade menor ou igual a 5\%, ou seja, provavelmente não seriam encontradas a não ser que se possa afirmar que há, sim, uma associação entre a categoria enfatizada na frase e o documento programático que a contém. 
Tabela 2 - Distribuição de frases entre os domínios, por programa (Resíduos ajustados entre parênteses) ${ }^{13}$

\begin{tabular}{|c|c|c|c|c|c|c|c|}
\hline \multirow{2}{*}{\multicolumn{2}{|c|}{ Domínio }} & \multicolumn{6}{|c|}{ Documento } \\
\hline & & \multirow{2}{*}{ 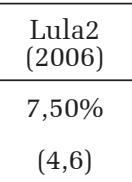 } & \multirow{2}{*}{$\begin{array}{c}\begin{array}{c}\text { Dilma1 } \\
(2010)\end{array} \\
16,20 \% \\
\mathbf{( 1 0 , 9 )}\end{array}$} & \multirow{2}{*}{$\begin{array}{c}\text { Dilma2 } \\
(2014)\end{array}$} & \multirow{2}{*}{$\begin{array}{c}\begin{array}{c}\text { Alkmin } \\
(2006)\end{array} \\
1,00 \% \\
(-5,7)\end{array}$} & \multirow{2}{*}{$\begin{array}{c}\begin{array}{c}\text { Serra } \\
(2010)\end{array} \\
2,90 \% \\
(-1,7)\end{array}$} & \multirow{2}{*}{$\begin{array}{c}\begin{array}{c}\text { Aécio } \\
(2014)\end{array} \\
3,10 \% \\
(-0,6)\end{array}$} \\
\hline 0 & Não classificáveis & & & & & & \\
\hline 1 & Relações exteriores & $\begin{array}{c}4,90 \% \\
(2,3)\end{array}$ & $\begin{array}{c}8,30 \% \\
(4,8)\end{array}$ & $\begin{array}{c}3,00 \% \\
(0,0)\end{array}$ & $\begin{array}{c}4,30 \% \\
(3,4)\end{array}$ & $\begin{array}{l}1,60 \% \\
(-4,9)\end{array}$ & $\begin{array}{c}2,00 \% \\
(-1,8)\end{array}$ \\
\hline 2 & $\begin{array}{l}\text { Liberdade e } \\
\text { democracia }\end{array}$ & $\begin{array}{c}2,30 \% \\
(0,7) \\
\end{array}$ & $\begin{array}{c}6,10 \% \\
(4,9) \\
\end{array}$ & $\begin{array}{c}1,90 \% \\
(0,0) \\
\end{array}$ & $\begin{array}{c}0,50 \% \\
(-4,5) \\
\end{array}$ & $\begin{array}{c}1,10 \% \\
(-3,3)\end{array}$ & $\begin{array}{c}4,70 \% \\
(\mathbf{6 , 7 )}\end{array}$ \\
\hline 3 & Sistema político & $\begin{array}{c}18,60 \% \\
(\mathbf{5 , 9})\end{array}$ & $\begin{array}{c}16,70 \% \\
(3,5)\end{array}$ & $\begin{array}{c}8,80 \% \\
(-0,8)\end{array}$ & $\begin{array}{c}11,40 \% \\
(2,1) \\
\end{array}$ & $\begin{array}{l}7,30 \% \\
\mathbf{( - 5 , 4 )} \\
\end{array}$ & $\begin{array}{c}9,40 \% \\
(-0,6)\end{array}$ \\
\hline 4 & Economia & $\begin{array}{c}23,30 \% \\
(-4,4) \\
\end{array}$ & $\begin{array}{c}17,10 \% \\
(-5,3) \\
\end{array}$ & $\begin{array}{c}38,90 \% \\
(2,5)\end{array}$ & $\begin{array}{c}41,00 \% \\
(7,1)\end{array}$ & $\begin{array}{c}34,00 \% \\
(0,9)\end{array}$ & $\begin{array}{c}25,10 \% \\
(-5,6)\end{array}$ \\
\hline 5 & $\begin{array}{l}\text { Bem estar e qualidade } \\
\text { de vida }\end{array}$ & $\begin{array}{c}34,60 \% \\
(-0,7)\end{array}$ & $\begin{array}{c}25,90 \% \\
(-3,4)\end{array}$ & $\begin{array}{c}37,00 \% \\
(0,3)\end{array}$ & $\begin{array}{c}28,40 \% \\
(-7,2)\end{array}$ & $\begin{array}{c}40,30 \% \\
(4,9)\end{array}$ & $\begin{array}{c}42,60 \% \\
(4,2)\end{array}$ \\
\hline 6 & Estrutura da sociedade & $\begin{array}{c}4,40 \% \\
(-0,7)\end{array}$ & $\begin{array}{c}6,10 \% \\
(0,7) \\
\end{array}$ & $\begin{array}{c}3,70 \% \\
(-1,4)\end{array}$ & $\begin{array}{l}4,20 \% \\
(-1,8)\end{array}$ & $\begin{array}{c}5,20 \% \\
(0,3) \\
\end{array}$ & $\begin{array}{c}7,00 \% \\
(2,8)\end{array}$ \\
\hline 7 & Grupos sociais & $\begin{array}{c}4,40 \% \\
(-2,1)\end{array}$ & $\begin{array}{c}3,50 \% \\
(-2,1)\end{array}$ & $\begin{array}{c}2,50 \% \\
\mathbf{( - 3 , 8 )}\end{array}$ & $\begin{array}{c}9,10 \% \\
(3,8)\end{array}$ & $\begin{array}{c}7,60 \% \\
(1,5)\end{array}$ & $\begin{array}{c}6,00 \% \\
(-1,2)\end{array}$ \\
\hline Total & $\begin{array}{l}\% \\
(\mathrm{~N})\end{array}$ & $\begin{array}{c}100,00 \% \\
(387)\end{array}$ & $\begin{array}{c}100,00 \% \\
(228)\end{array}$ & $\begin{array}{c}100,00 \% \\
(432)\end{array}$ & $\begin{array}{c}100,00 \% \\
(1432)\end{array}$ & $\begin{array}{c}100,00 \% \\
(2216)\end{array}$ & $\begin{array}{c}100,00 \% \\
(880)\end{array}$ \\
\hline
\end{tabular}

Fonte: Elaborada pelos autores.

para governar), ambas do domínio 3 - Sistema Político. Por fim, em 2014, a ênfase do segundo programa de Dilma recai na categoria 503a (igualdade socioeconômica de classe), o que atesta a ênfase do discurso de campanha na defesa da redução da pobreza no país. Já os programas do PSDB enfatizam significativamente mais a categoria 304 (corrupção política) em 2006, a categoria 411a (infraestrutura, indústria, transporte e logística) em 2010 e a categoria 201 (liberdades e direitos humanos) em 2014. É digno de nota que, entre 2010 e 2014, os programas do PSDB mudam significativamente sua estratégia de campanha, dado que a categoria mais salientada em 2010 será a mais subutilizada na eleição seguinte $(-7,8)$.

Se ampliarmos o foco de análise e considerarmos os domínios que mais se destacam ${ }^{13}$ Os dados podem ser disponibilizados mediante solicitação direta aos autores. em cada programa, identificamos que os programas do PT gravitam em torno da dimensão 2 (democracia e cidadania, em 2010) e da dimensão 3 (eficiência governamental e crítica a governos anteriores, em 2006, e competência para governar, em 2010). Contudo ambas sofrem uma drástica redução e possuem importância residual no programa de 2014, em que a economia foi a dimensão mais enfatizada. Os programas do PSDB, por sua vez, enfatizam principalmente o domínio 4 (incentivos, regulação e objetivos econômicos, em 2006, e infraestrutura, em 2010), destacando-se também os domínios 5 (saúde, em 2010, e educação, em 2014) e 2 (liberdades e direitos humanos ${ }^{14}$, em 2014).

O Gráfico 1 ilustra a distribuição das frases em cada documento em termos de porcentagens:

${ }^{14}$ Voltaremos a esse tema quando analisarmos a saliência de temas relacionados a questões pós-materialistas. 
Gráfico 1 - Distribuição dos conteúdos dos programas entre os domínios

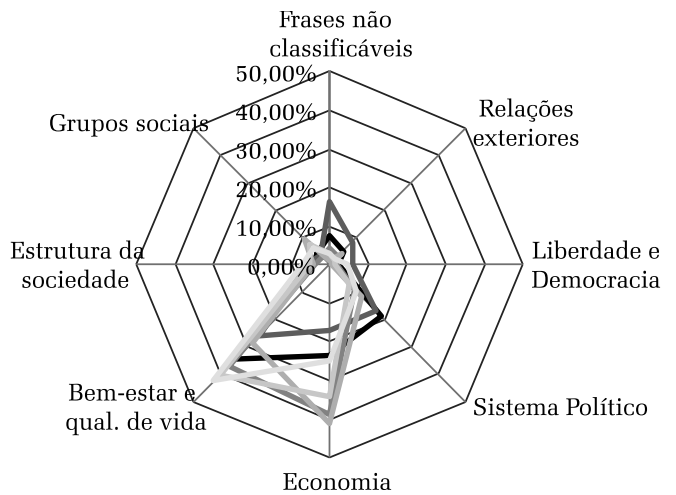

-PT 2006

—PT 2010

- PT2014

-PSDB 2006

-PSDB 2010

PSDB 2014

Fonte: Elaborada pelos autores.

Podemos, assim, afirmar que a ênfase atribuída a cada tipo de questão não é aleatória, nem indistinta entre os programas. Ao contrário, cada um dos documentos analisados enfatiza mais uma categoria diferente: identificamos que, nas duas primeiras eleições, o PT prioriza a discussão da política, e o PSDB a da economia. Mesmo quando enfatiza a corrupção, como em 2006, a denúncia da corrupção está quase sempre fundada na perda de recursos que ela provoca. Essa distinção sugere que os candidatos dos dois partidos, de fato, escolhem áreas da agenda pública para enfatizar nas suas plataformas e construir suas próprias agendas. Nas duas primeiras eleições, enquanऽั to o PT insiste em chamar a atenção para uma 家 maneira específica de condução da política e da gestão do governo, o PSDB especializa-se em evidenciar problemas econômicos oriundos dessa mesma gestão. Esse padrão nas ênfases dos programas não se repete em 2014, quando o $\dot{2}$ programa do segundo governo de Dilma avança sobre o tema da economia e diminui significativamente a ênfase no sistema político, enquanto o programa de Aécio abandona a ênfase na economia e prioriza o debate acerca do bem-estar e da qualidade de vida, temas até então mais enfatizados nos programas do PT.

\section{OS PROGRAMAS DE GO- VERNO E AS DIMENSÕES DA COMPETIÇÃO POLÍTICA}

A codificação das frases em categorias permite situar cada programa em escalas de posicionamento político, tais como a escala esquerda-direita e a escala materialismo-pós-materialismo.

A primeira tem constituído a dimensão fundamental nas análises da competição política, pelo menos desde Downs (1999) e também tem sido objeto de longo debate tanto no que se refere aos conceitos envolvidos quanto no que se refere à sua operacionalização (Madeira; Tarouco, 2011).

O MRG/CMP/MARPOR subsidiou a elaboração de uma escala para mensurar a posição dos partidos na dimensão esquerda-direita (Budge et al. 2001; Laver; Budge, 1992), que já foi aplicada inclusive aos programas de governo de Dilma e Serra (López; Miranda; Valenzuela-Gutiérre, 2013). Tal escala também já foi adaptada para refletir melhor os termos específicos da competição política no Brasil. A escala original do MRG/MARPOR é construída com categorias que refletem elementos considerados típicos de esquerda e de direita, no contexto europeu, onde sua aplicação é extensa e aparentemente incontroversa. Para analisar a ideologia dos manifestos partidários no Brasil, entretanto, propusemos uma adaptação da escala para adequá-la às especificidades históricas brasileiras (Tarouco; Madeira, 2013). Nossa medida de ideologia, então, inclui, além de questões econômicas e de redistribuição, o aspecto do papel do Estado na manutenção da ordem através das Forças Armadas. ${ }^{15}$

${ }^{15}$ Elementos relativos a valores e costumes não são incluídos na escala porque entendemos que compõem outra dimensão, que pode ser chamada de eixo progressista-conservador, perpendicular ao eixo esquerda-direita, e que não se confunde com ele. Não é possível tratar de mais essa dimensão nos limites deste artigo, mas é razoável esperar que ela aproxime os documentos aqui analisados, especialmente devido à presença de partidos ditos evangélicos nas duas coligações. 
Tabela 3 - Cálculo da posição na escala esquerda - direita

\begin{tabular}{|c|c|c|c|c|c|c|}
\hline \multirow{2}{*}{ Categoria } & \multicolumn{6}{|c|}{ Documento } \\
\hline & Lula (2006) & $\begin{array}{l}\text { Dilma } \\
(2010)\end{array}$ & $\begin{array}{l}\text { Dilma } \\
(2014)\end{array}$ & $\underset{(2006)}{\text { Alkmin }}$ & $\begin{array}{c}\text { Serra } \\
(2010)\end{array}$ & $\begin{array}{l}\text { Aécio } \\
\text { (2014) }\end{array}$ \\
\hline \multicolumn{7}{|l|}{ Categorias de direita: } \\
\hline Forças Armadas: positivo & 1,6 & 0,9 & 0,0 & 2,6 & 0,3 & 0,1 \\
\hline Livre iniciativa & 0,0 & 0,0 & 0,0 & 0,3 & 0,2 & 0,0 \\
\hline Incentivos & 2,8 & 2,2 & 6,5 & 6,9 & 1,6 & 5,0 \\
\hline Ortodoxia econômica & 0,0 & 0,0 & 0,0 & 0,8 & 1,3 & 0,3 \\
\hline Limitação do Welfare State & 0,0 & 0,0 & 0,0 & 0,0 & 0,0 & 0,0 \\
\hline Classe média, grupos profissionais & 0,0 & 0,0 & 0,0 & 0,0 & 0,0 & 0,0 \\
\hline Total direita & 4,4 & 3,1 & 6,5 & 10,6 & 3,4 & 5,4 \\
\hline \multicolumn{7}{|l|}{ Categorias de esquerda: } \\
\hline Regulação do mercado & 0,0 & 0,0 & 0,0 & 1,7 & 0,1 & 3,1 \\
\hline Planejamento econômico & 0,5 & 1,3 & 0,0 & 0,0 & 0,1 & 0,0 \\
\hline Economia controlada & 0,0 & 0,0 & 0,0 & 0,0 & 0,0 & 0,1 \\
\hline Análise marxista & 0,0 & 0,0 & 0,0 & 0,0 & 0,0 & 0,0 \\
\hline Expansão do Welfare State & 10,9 & 7,0 & 8,8 & 13,5 & 19,4 & 16,1 \\
\hline Classes trabalhadoras: positivo & 1,0 & 2,2 & 0,0 & 2,9 & 0,6 & 0,0 \\
\hline Total esquerda & 12,4 & 10,5 & 8,8 & 18,1 & 20,2 & 19,3 \\
\hline Direita - Esquerda & $-8,0$ & $-7,5$ & $-2,3$ & $-7,5$ & $-16,8$ & $-13,9$ \\
\hline
\end{tabular}

Fonte: Elaborado pelos autores.

A Tabela 3 mostra o cálculo da posição na escala esquerda-direita dos programas de governo das coligações do PT e do PSDB de 2006 a 2014, de acordo com as porcentagens de texto dedicadas a categorias indicativas de esquerda e de direita, conforme nossa adaptação da escala do MRG/MARPOR ${ }^{16}$ (Tarouco; Madeira 2013)

A mensuração da posição dos programas de governo na escala esquerda-direita é bem menos promissora do que a sua aplicação a manifestos partidários, pela natureza mais pragmática, de campanha, daquele tipo de documentos. Espera-se, como, de fato, outros

${ }^{16}$ A escala esquerda-direita do MRG/MARPOR (Budge et al 2001; Laver; Budge 1992) subtrai a proporção de texto dos documentos dedicada a categorias indicativas da posição de esquerda do total da proporção de texto dedicada às categorias indicativas da posição de direita. Valores negativos representam posições de esquerda, e positivos, posições de direita. Nossa escala adota o mesmo procedimento para cálculo da posição, mas substitui algumas categorias para refletir mais adequadamente significados específicos que esquerda e direita assumem no Brasil (Tarouco; Madeira 2013). trabalhos já encontraram (Budge; McDonald 2012), que programas de governo, pela sua natureza transitória e seu apelo eleitoral, ${ }^{17}$ contenham uma proporção muito maior de texto não relacionado a preferências em termos de políticas públicas do que os manifestos partidários. Além disso, os programas de governo exprimem as propostas da coalizão, não apenas do partido. Levando-se em consideração o alto grau de heterogeneidade das coalizões eleitorais e governamentais observadas no Brasil, é possível entender que, nesses documentos, não seja reforçado o apelo ideológico. Certamente, é a isso que se deve a distância entre os resultados da Tabela 3 e a classificação usualmente atribuída aos partidos dos candidatos à presidência. Apesar de o PT ser

17 É plausível argumentar que a definição da estratégia eleitoral também tenha impacto significativo no quanto uma candidatura revelará suas inclinações ideológicas e também em quais dessas inclinações serão ressaltadas e retiradas de cena ao longo da campanha. 
reiteradamente considerado, na literatura, um partido mais à esquerda que o PSDB, nos textos dos programas de governo das coligações encabeçadas pelos seus candidatos, as posições se invertem.

No caso dos programas de governo brasileiros, apresentados por coligações amplas e frequentemente inconsistentes do ponto de vista ideológico (Krause, 2010), a mensuração da posição na escala esquerda-direita, através da análise de conteúdo, deve levar em conta que os textos precisam acomodar, em alguma medida, preferências ideológicas dos diferentes partidos coligados, como foi dito anteriormente, além do discurso de campanha eleitoral. ${ }^{18}$

Assim mesmo, é interessante observar a variação dessas posições em cada programa de coligação, ao longo do tempo. O Gráfico 2 ilustra essa variação.

Gráfico2 - Posição dos programas na escala EsquerdaDireita

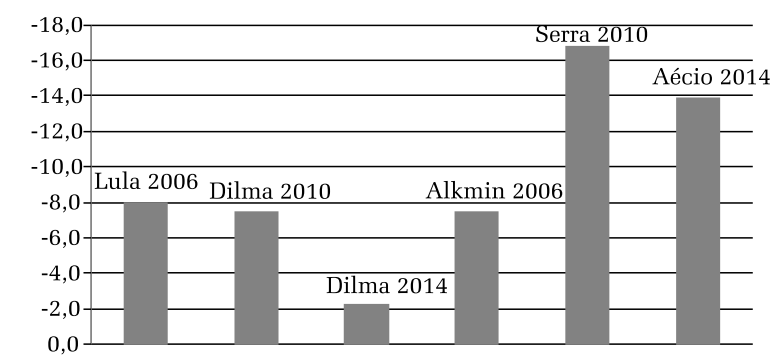

Fonte: Elaborada pelos autores.

$\stackrel{\infty}{\lfloor} \quad$ Essa variação no tempo poderia ser um reflexo da mudança na composição partidária das coligações. ${ }^{19}$ Se essa fosse a explicação, entretanto, o movimento do PT se afastando da ลิ esquerda para o centro, de 2010 para 2014, es¿. taria relacionado à saída do PSB, PSC e PTC e $\dot{\text { à }}$ entrada de PP, PROS e PSD na coligação. Da iे mesma forma, o movimento do PSDB em direção à esquerda, de 2006 para 2010, estaria rela-

$\stackrel{\pi}{\perp}{ }^{18}$ Compreender a medida dessa acomodação demanda๘ ria comparar as posições dos programas de governo com

I a média das posições dos partidos, mas isso exigiria que

todos os manifestos fossem submetidos à mesma análise

U manual de conteúdo, o que não é possível para os limi-

$\checkmark$ tes deste artigo, mas está no horizonte de nossa agenda de pesquisa.

${ }^{19}$ Ver Quadro 1 e notas de rodapé no 10 e no 18. cionado à entrada do PMN, PPS, PTB e PT do B na coligação. Nos dois casos, a reconfiguração das coligações não parece ser uma explicação satisfatória, porque os partidos envolvidos são geralmente referidos, na literatura, ou como pouco programáticos, ou como ideologicamente heterogêneos internamente.

Para além dos elementos destacados anteriormente, a clivagem governo versus oposição, articulada com elementos do contexto eleitoral, pode auxiliar na compreensão e na leitura desses dados. Diferentemente de 2006 e 2010, em 2014, a candidatura do PT teve a árdua tarefa de prestar contas e defender uma gestão muito criticada, principalmente em função do desempenho da economia ao longo da gestão anterior.

Por fim, chama a atenção também que todos os programas se situem no campo da esquerda, o que indica ausência, no período analisado, no plano eleitoral, de candidatura que se assuma como de direita e se torne competitiva a ponto de chegar ao segundo turno.

Outra dimensão importante a ser considerada na competição política e que pode ser localizada nos programas de governo é a dimensão do pós-materialismo, que compreende aqueles valores e preferências que não se enquadram na distinção entre esquerda e direita (ambas atinentes a questões da sobrevivência e segurança material), mas se referem a valores de autoexpressão e qualidade de vida. São típicas do pós-materialismo as bandeiras ambientalistas, da liberdade de expressão e da defesa do respeito às diferenças. Preferências pós-materialistas tenderiam a se manifestar em sociedades economicamente avançadas, onde os cidadãos já desfrutariam de segurança econômica e física.

Essa é uma perspectiva herdeira da teoria da modernização (Lipset, 1959; Przeworski et al, 2000), segundo a qual os níveis de desenvolvimento econômico explicariam a probabilidade de sucesso da democracia. A esse argumento Inglehart (1990, 1993, 2012) adicionou variáveis da cultura política para afirmar que, 
com o crescimento da capacidade econômica, é possível observar um aumento nas capacidades cognitivas, “ $[\ldots]$ o que, por sua vez, torna as pessoas material, intelectual e socialmente independentes” (Inglehart; Welzel 2009).

Segundo Inglehart $(1990,2007)$, as sociedades industriais avançadas estariam passando por uma mudança cultural em que os valores relativos à sobrevivência e à segurança (tanto material como física) estariam dando espaço para valores de autoexpressão e qualidade (não econômica) de vida. Em sociedades em que as questões distributivas e as disputas econômicas e sociais já estão minimamente amenizadas, podem surgir demandas de um novo tipo, tais como preservação ambiental, respeito a minorias e liberdades individuais de todos os tipos. A emergência desses valores determinaria a instalação de uma nova dimensão política, entre o polo materialista e o pós-materialista, ao longo da qual se posicionariam indivíduos e partidos.

É razoável esperar que valores pósmaterialistas estejam presentes entre as preferências políticas de partidos em países de economia desenvolvida e que possam, portanto, ser detectados em seus documentos programáticos. No Brasil, o público-alvo do discurso político é muito heterogêneo, devido à grande desigualdade social. Qualquer candidato que busque votos, em âmbito nacional, precisa oferecer um leque amplo de políticas, de modo a atender, simultaneamente, a eleitorados com demandas muito distintas, que incluem desde o combate à miséria até a proteção ambiental. Assim, faz sentido que os programas contemplem tanto questões materialistas (dirigidas à parcela do eleitorado mais atingida por problemas de insegurança social e econômica) quanto questões pós-materialistas (dirigidas aos estratos do eleitorado que cresceram em ambiente de segurança econômica). ${ }^{20}$

${ }^{20} \mathrm{O}$ argumento da literatura sobre a emergência dos valores pós-materialistas (Inglehart, 1990, 2007) é de que ela seja mais provável em gerações que cresceram em condições de segurança material, por exemplo, com acesso a políticas de bem-estar social, e menos provável naquelas
gerações que cresceram em condições materiais adversas,
A inclusão da dimensão pós-materialista na análise da competição política no Brasil se justifica, portanto, pela expectativa teórica de que produza distinções entre plataformas e, pela sua presença na literatura empírica internacional, como uma dimensão nova e importante na competição partidária. Nesta seção, procuramos identificar se a dimensão pós-materialista distingue os programas de governo das coligações encabeçadas por PT e PSDB em 2006, 2010 e 2014. Se a inconsistência das coligações, em termos ideológicos, aproxima os conteúdos dos programas, é possível que a dimensão pós-materialista as diferencie. Até onde sabemos, não há, na produção do MRG/ CMP/MARPOR, uma escala elaborada para mensurar essa dimensão, nos moldes da escala esquerda-direita, por exemplo. O conteúdo pós-materialista já foi identificado em manifestos de partidos europeus (Musa, 2006), mas utiliza categorias elaboradas ad hoc, não aquelas do esquema de codificação do MRG/CMP.

Como nosso objetivo é produzir uma análise minimamente comparável, optamos por selecionar, entre as várias categorias presentes no esquema de codificação do MRG/ CMP, aquelas que refletem valores pós-materialistas. São elas: Liberdade e direitos humanos (201), Proteção do meio ambiente (501), Cultura (502), Igualdade de ciclo de vida, de gênero, étnico-racial e outras, exceto igualdade econômica e social (503b, 503c, 503d e 503e) e Grupos minoritários e desfavorecidos (705). Para montar a escala de materialismo-pós-materialismo, propomos como indicativos de preferências materialistas todas as categorias do domínio Economia (4) exceto a categoria Anti-crescimento (416), além das categorias Igualdade socioeconômica (503a), Expansão do Welfare State (504) e Lei e ordem (605).

A Tabela 4 mostra a proporção de texto dedicada às categorias do pós-materialismo

por exemplo, em contextos de devastação por guerras. No caso do Brasil, as condições materiais que afetam os valores das pessoas na vida adulta não variam uniformemente no tempo, de uma geração para outra, mas sim dentro de cada geração, de um estrato social para outro. 
Tabela 4 - Porcentagem das categorias indicativas de valores pós-materialistas

\begin{tabular}{l|c|c|c|c|c|c}
\hline \multirow{2}{*}{ Categorias } & \multicolumn{7}{|c}{ Documento } \\
\cline { 2 - 8 } & $\begin{array}{c}\text { Lula2 } \\
(2006)\end{array}$ & $\begin{array}{c}\text { Dilma1 } \\
(2010)\end{array}$ & $\begin{array}{c}\text { Dilma2 } \\
(2014)\end{array}$ & $\begin{array}{c}\text { Alckmin } \\
(2006)\end{array}$ & $\begin{array}{c}\text { Serra } \\
(2010)\end{array}$ & $\begin{array}{c}\text { Aécio } \\
(2014)\end{array}$ \\
\hline Liberdade e direitos humanos & 1,3 & 0,4 & 0,2 & 0,1 & 0,7 & 3,2 \\
\hline Proteção do meio ambiente & 3,4 & 4,4 & 3,0 & 3,3 & 5,4 & 5,1 \\
\hline Cultura & 2,6 & 2,6 & 4,9 & 5,7 & 4,6 & 6,9 \\
\hline Igualdade (exceto social) & 9,6 & 0,4 & 2,3 & 0,7 & 4,4 & 2,9 \\
\hline Grupos minoritários desfavorecidos & 0,0 & 0,0 & 0,2 & 0,3 & 2,3 & 1,0 \\
\hline Total & 16,9 & 7,8 & 10,6 & 10,1 & 17,4 & 19,1 \\
\hline
\end{tabular}

Fonte: Elaborada pelos autores.

* Agrega as subcategorias 503b (igualdade de ciclo de vida), 503c (igualdade de gênero) e 503d (igualdade étnico-racial) e 503e (igualdade em outros grupos). A lista completa de categorias está disponível em Alonso, Volkens e Gómez (2012)

pelos seis programas analisados.

Observa-se a presença de questões da agenda pós-materialista em todos os programas de governo analisados, mas com uma grande variação de ênfases. O programa do PT de 2010 é o que menos espaço dedica a essas questões, e o do PSDB de 2014 o que dedica mais. Surpreende ${ }^{21}$ que temas da agenda pós-materialista tenham tido sua ênfase reduzida pela metade no programa do PT, caindo de $16 \%$ para menos de $8 \%$ entre 2006 e 2010 e aumentando discretamente sua incidência em 2014. A Tabela 4 permite identificar que tal variação está claramente relacionada à variação identificada nas subcategorias não econômicas da categoria "Igualdade", relativas ao pós-ma亏ิ terialismo. Esse é mais um indício de que as : agendas dos dois partidos são bem distintas e $\stackrel{\text { L }}{\mathrm{L}}$ variam no tempo.

Em cada uma das três eleições, os dois candidatos distinguem-se visivelmente no que concerne à ênfase em questões pós-materialisํ. tas. Em 2006, foi o programa de Lula o que $\stackrel{2}{\infty}$ conferiu mais espaço a essa agenda específi$\dot{a}$ ca, enfatizando principalmente os direitos de iे igualdade étnica, de gênero e de ciclo de vida, enquanto Alckmin se ocupava em denunciar a corrupção política. Em 2010 e em 2014, os ஸึ papéis se inverteram: foram os programas de José Serra e Aécio Neves que dedicaram mais ${ }^{21}$ Seria razoável esperar uma variação menor, especialmente depois das políticas sociais redistributivas dos mandatos anteriores. atenção à agenda pós-materialista, defendendo especialmente políticas dirigidas a grupos minoritários específicos, enquanto os dois programas de Dilma Rousseff enfatizavam questões econômicas e sociais, bem como reafirmavam a competência para governar.

Os dados apontam que a agenda pós-materialista pode ter sido a grande aposta do PSDB em 2010 e em 2014, depois do avanço dos programas sociais durante os governos anteriores. Assim, o PSDB passou a chamar mais a atenção para questões não resolvidas pelas políticas redistributivas implementadas pelos governos do PT. Esse achado está de acordo com a expectativa da saliency theory, de que os partidos escolhem enfatizar temas em que veem mais chance de serem percebidos como bem sucedidos e preterem temas em que seus adversários aparentam maior competência.

A interpretação das proporções de texto dedicadas a questões pós-materialistas, entretanto, deve ser ponderada pela proporção de texto dedicada a questões materialistas, através da escala proposta acima. Assim como a escala esquerda-direita do MRG/CMP, essa escala que estamos propondo para mensurar o conteúdo pós-materialista subtrai a proporção de texto dos documentos dedicada a categorias do materialismo do total da proporção de texto dedicada às categorias do pós-materialismo. Valores negativos representam posições materialistas e valores positivos representam 
Tabela 5 - Cálculo da posição dos programas na escala de pós-materialismo

\begin{tabular}{|c|c|c|c|c|c|c|c|}
\hline \multirow{2}{*}{ 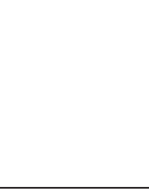 } & \multirow{2}{*}{ Categoria } & \multicolumn{6}{|c|}{ Documento } \\
\hline & & \multirow{2}{*}{ 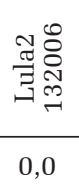 } & \multirow{2}{*}{ 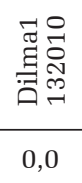 } & \multirow{2}{*}{ 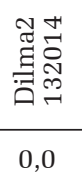 } & \multirow{2}{*}{ 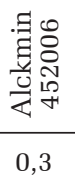 } & \multirow{2}{*}{ 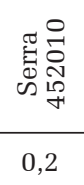 } & \multirow{2}{*}{ 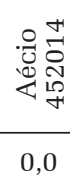 } \\
\hline 401 & Liberdade de mercado & & & & & & \\
\hline 402 & Incentivos & 2,8 & 2,2 & 6,5 & 6,9 & 1,6 & 5,0 \\
\hline 403 & Regulação do mercado & 0,0 & 0,0 & 0,0 & 1,7 & 0,1 & 3,1 \\
\hline 404 & Planejamento econômico & 0,5 & 1,3 & 0,0 & 0,0 & 0,1 & 0,0 \\
\hline 405 & Corporativismo & 0,3 & 0,0 & 0,0 & 0,0 & 0,0 & 0,0 \\
\hline 406 & Protecionismo: positivo & 1,0 & 0,0 & 0,7 & 0,4 & 0,0 & 0,0 \\
\hline 407 & Protecionismo: negativo & 0,0 & 0,0 & 0,0 & 0,0 & 0,0 & 0,0 \\
\hline 408 & Metas econômicas & 2,8 & 0,9 & 11,8 & 10,9 & 6,7 & 5,3 \\
\hline 409 & Gerenciamento keynesiano da demanda & 0,3 & 0,0 & 0,7 & 0,1 & 0,0 & 0,0 \\
\hline 410 & Produtividade & 1,8 & 1,3 & 0,7 & 2,7 & 0,5 & 0,8 \\
\hline 411 & Tecnologia e infraestrutura & 13,7 & 11,4 & 18,5 & 17,2 & 23,4 & 10,3 \\
\hline 412 & Economia controlada & 0,0 & 0,0 & 0,0 & 0,0 & 0,0 & 0,1 \\
\hline 413 & Nacionalização & 0,0 & 0,0 & 0,0 & 0,0 & 0,0 & 0,0 \\
\hline 414 & Ortodoxia econômica & 0,0 & 0,0 & 0,0 & 0,8 & 1,3 & 0,3 \\
\hline 415 & Análise marxista & 0,0 & 0,0 & 0,0 & 0,0 & 0,0 & 0,0 \\
\hline $503(\mathrm{a})$ & Igualdade socioeconômica & 0,8 & 2,2 & 6,7 & 0,0 & 0,5 & 1,5 \\
\hline 504 & Expansão do Welfare State & 10,6 & 7,0 & 8,8 & 12,4 & 19,4 & 16,1 \\
\hline 605 & Lei e ordem & 4,4 & 6,1 & 3,0 & 4,1 & 5,1 & 5,5 \\
\hline \multicolumn{2}{|c|}{ Subtotal: materialismo } & 39,0 & 32,4 & 57,4 & 57,5 & 58,9 & 48,0 \\
\hline 201 & Liberdade e direitos humanos & 1,3 & 0,4 & 0,2 & 0,1 & 0,7 & 3,2 \\
\hline 501 & Proteção ambiental & 3,4 & 4,4 & 3,0 & 3,3 & 5,4 & 5,1 \\
\hline 502 & Cultura & 2,6 & 2,6 & 4,9 & 5,7 & 4,6 & 6,9 \\
\hline $\begin{array}{c}503 \text { (b, c, } \\
\text { d, e) }\end{array}$ & Igualdade (exceto socioeconômica) & 9,6 & 0,4 & 2,3 & 0,7 & 4,4 & 2,9 \\
\hline 705 & Grupos minoritários & 0,0 & 0,0 & 0,2 & 0,3 & 2,3 & 1,0 \\
\hline \multicolumn{2}{|c|}{ Subtotal: pós-materialismo } & 16,9 & 7,8 & 10,6 & 10,1 & 17,4 & 19,1 \\
\hline \multicolumn{2}{|c|}{ Posição na escala (Pós-mat. - Mat.) } & $-22,1$ & $-24,6$ & $-46,8$ & $-47,4$ & $-41,5$ & $-28,9$ \\
\hline
\end{tabular}

posições pós-materialistas. A Tabela 5 mostra o cálculo da posição na escala para os seis documentos analisados.

No que diz respeito aos programas do PSDB, identifica-se uma estabilidade muito grande no alto peso das categorias relacionadas ao materialismo $(57,5,58,9$ e 57,4 , respectivamente). Essa estabilidade é menor (mas, ainda assim, significativa e com tendência ao aumento) no peso das categorias afeitas ao pós- -materialismo (10,1, 17,4 e 19,1, respectivamente). Já no PT, a influência do materialismo é significativamente mais volátil, caindo de 39 para 32,4 e subindo abruptamente para 57,4 no programa de 2014. Embora menor, essa alta volatilidade é encontrada também nas categorias representativas de questões pós-materialistas, dado que o seu peso cai pela metade entre 2006 e 2010 e volta a subir em 2014 (16,9, 7,8 e 10,6, respectivamente). 
Gráfico 3 - Posição dos programas na escala de Pós-materialismo

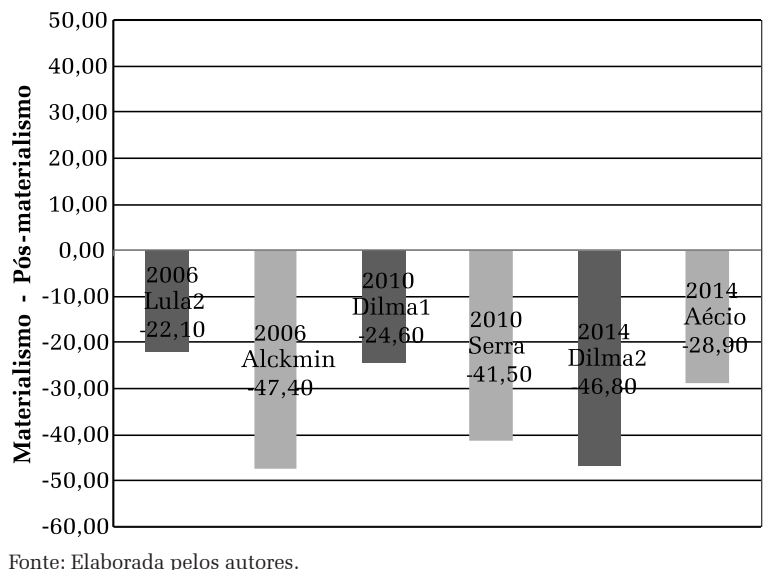

Há várias interpretações possíveis desses achados. Em primeiro lugar, todos os programas de governo analisados se situam no campo materialista da escala, ou seja, as agendas tanto do PT quanto do PSDB, nas campanhas presidenciais de 2006, 2010 e de 2014, privilegiaram as questões de segurança material, tanto econômica e social como física em comparação com as questões pós-materialistas. Para além dessa primeira aproximação aos dados, outra continuidade identificada entre 2006 e 2010 é o fato de o PSDB priorizar mais a agenda materialista que o PT. Ainda entre aquelas duas eleições, identifica-se a pouca va-

A riação entre os programas de cada partido no ․ valor final da escala (PSDB variando na casa dos -40 e PT, na casa dos - 20).

Contudo, em 2014, se constata uma troca quase perfeita na hierarquia dos temas que marcam a agenda proposta por cada candidaนิ tura: o segundo programa de Dilma Rousseff, ¿. na casa dos -46 , e Aécio Neves, na casa dos ¿ -28. Tal achado corrobora a informação destaiे cada anteriormente, que aponta para o fato de que, entre 2010 e 2014, houve uma modificação significativa nas ênfases de cada partido. ${ }^{22}$

${ }^{22}$ Esse achado está de acordo com os argumentos de Gatto e Power (2016), que identificam que a probabilidade de adotar um discurso pós-materialista varia de acordo com as condições materiais.

\section{CONSIDERAÇÕES FINAIS}

Neste trabalho, buscamos contribuir para o mapeamento de um terreno ainda muito pouco explorado pela Ciência Política brasileira: análise de programas de governo. A resposta à questão que o norteou não é simples, mas alguns dos achados da pesquisa auxiliam no exame das ênfases das candidaturas dos dois partidos e serão aqui destacados. A julgar pelos programas, cabe salientar o papel central que questões relacionadas à economia e ao estado de bem-estar possuem na agenda eleitoral de ambos os partidos. A atuação e a posição do estado como indutor do desenvolvimento econômico e garantidor de serviços (saúde, educação, etc.) ao cidadão estruturam todos os programas aqui examinados. O que existe de diferente entre os partidos, em 2006 e em 2010, é que, entre esses dois domínios, o PT priorizou o estado de bem-estar, enquanto que o PSDB tendeu a priorizar a economia.

Em 2014, essa relação se modifica. É possível que o aumento nas ênfases em bemestar social pelo PSDB, após 2010, esteja relacionado ao sucesso dos programas de transferência de renda e suas condicionalidades (obrigatoriedade de crianças matriculadas, controle médico, cartão de vacina em dia, etc.).

Embora o PSDB reclame a identidade social democrata em seus documentos, seu enfoque temático, em duas das três eleições aqui examinadas, o afasta desse ideário político, uma vez que a ênfase nas categorias do domínio 4, economia, o aproximariam de um posicionamento de partido de centro direita. Não obstante, o aumento da ênfase do partido em temáticas de bem estar na última eleição pode sinalizar uma mudança de estratégia frente à demanda por esse tipo de políticas. Como sinalizamos anteriormente, o partido busca chamar mais atenção para as questões não resolvidas pelo PT. Por outro lado, o PT apresenta uma plataforma com forte destaque 
para as questões relacionadas ao bem-estar nas duas primeiras eleições e parece se inserir, em 2014, mais fundo na agenda econômica, o que, possivelmente, está relacionado ao desafio de prestar contas e defender a gestão anterior, criticada principalmente em função do desempenho da economia.

As distinções encontradas não correspondem, entretanto, a uma diferença entre governo e oposição, como seria de esperar, dada a bipolarização das disputas presidenciais. Todos os documentos analisados foram elaborados durante períodos em que o PT era governo e o PSDB oposição, ou seja, o status de incumbente ou desafiante não varia e, portanto, não pode ser a explicação para a variação nas ênfases de cada partido ao longo do tempo.

Salienta-se a variação encontrada nas ênfases atribuídas a temas da agenda pós-materialista. Por adaptação a imperativos eleitorais ou pelo esgotamento do potencial competitivo das bandeiras ideológicas tradicionais, em alguma medida, as demandas não econômicas de qualidade de vida tornam-se presentes nos programas de governo. A atenção a novos tipos de direitos, para cuja garantia as políticas sociais são insuficientes, passa a compartilhar algum espaço nas agendas dos partidos que polarizam a competição presidencial e pode revelar o modo como o Brasil se inseriu no processo da inflexão latino-americana, à esquerda.

Embora haja algumas questões que parecem pouco definidas quanto à preferência e às estratégias dos dois partidos, os programas constituem, sim, um rico instrumental analítico para se conhecerem as prioridades desses atores políticos. Tais prioridades, por sua vez, ajudam a compreender a competição partidária e as agendas de governos no Brasil.

Com a presente análise, podemos afirmar que as diferentes agendas do PT e do PSDB, nas últimas disputas presidenciais, publicadas em seus programas de governo, revelam preferências específicas. Contudo tais preferências não são estáticas, como mostra a inversão observada entre os dois partidos de 2010 para 2014, no que se refere às ênfases materialistas e pós-materialistas. O que sobrevive ao tempo e aos presumíveis ajustes das coligações não é exatamente o conteúdo das ênfases, mas a distinção entre duas alternativas facilmente identificáveis: as mudanças no tempo não aproximam os dois partidos. A inversão observada parece confirmar a expectativa da saliency theory de que as ênfases são escolhas estratégicas pautadas na dinâmica da competição.

Recebido para publicação em 20 de março de 2017 Aceito em 25 de julho de 2017

\section{REFERÊNCIAS}

ALONSO, S.; VOLKENS, A.; GÓMEZ, B. Análisis de contenido de textos políticos: Um enfoque cuantitativo. Madrid: Centro de Investigaciones Sociológicas, 2012. (Cuadernos Metodológicos, 47).

BENOIT, K.; LAVER, M.; MIKHAYLOV. Coder reliability and misclassification in Comparative Manifesto Project codings. 2008. Apresentado no $66^{\text {th }}$ MPSSA - Annual National Conference,Palmer House Hilton Hotel and Towers, 2008. p. 3-6.

BONNARDEL, P. The kappa coefficient: The measurement of Interrater agreement when the ratings are on categorical scales: The case of two raters. 2001. Disponível em: $<$ http:// kappa.chez-alice.fr/> . Acesso em: 22 jul. 2013.

BORGES, A.; LLOYD, R. Presidential coattails and electoral coordination in multilevel elections: Comparative lessons from Brazil. Electoral Studies, Amsterdam, v. 43, n.1, p. 104-114, 2016.

BUDGE, I. et al. Mapping policy preferences: estimates for parties, electors, and governments 1945-1998. Oxford: Oxford University Press, 2001.

BUDGE, I.; MCDONALD, M. Conceptualising and measuring 'centrism' correctly on the Left-Right scale (RILE) - without systematic bias. A general response by MARPOR. Electoral Studies, Amsterdam, v. 31, n. 3, p. 609-612, 2012.

BUDGE, I., ROBERTSON; D.; HEARL, D. (Ed.). Ideology, strategy, and party change: spatial analyses of post-war election programmes in 19 democracies. Cambridge: Cambridge University Press, 1987.

CARREIRÃO, Y. d. S. O sistema partidário brasileiro: um debate com a literatura recente. Revista Brasileira de Ciência Política, Brasília, DF, n. 14, p. 255-295, 2014.

CASTILLO, M.; PEREZ,V. Esencia y espacio: análisis de los programas del Frente Amplio y el Partido Nacional en las elecciones nacionales de 2009. In: BUQUET, D.; JHONSON, N. (Org.). Del Cambio a la Continuidad: Ciclo Electoral 2009-2010 en Uruguay. Montevideo: Fin Del siglo, 2010. p. 105-131.

COHEN, J. A coefficient of agreement for nominal scales. Educational and Psychological Measurement XX, v. 1, p. 37-46, 1960.

DOWNS, A. Uma teoria econômica da democracia. São Paulo: Edusp, 1999. 
DUVERGER, M. Os partidos políticos. 2. ed. . Rio de Janeiro: Zahar; Brasília, DF: UNB, 1980.

GATTO, M.; POWER, T. Postmaterialism and Political Elites: the value priorities of Brazilian federal legislators. Journal of Politics in Latin America, Hamburg, v.8, n.1, p. 33-68, 2016.

HIBBS JR, D. A. Political Parties and Macroeconomic Policy. The American Political Science Review, Baltimore, v. 71, n. 4, p. 1467-1487, 1977.

INGLEHART, R. Culture shift in advanced industrial society. Princeton: Princeton University Press, 1990.

INGLEHART, R. Democratização em perspectiva global. Opinião Pública, Campinas, v.1, n. 1, p. 9-67, 1993.

INGLEHART, R. A Revolução silenciosa na Europa: mudança intergeracional nas sociedades pós-industriais. Revista de Sociologia e Política, Curitiba, v. 20, n. 43, p. 159-191, 2012.

INGLEHART, R. Postmaterialist Values and the Shift from Survival to Self-Expression Values. In: DALTON, R. J.; KLINGEMANN, H.-D. (Ed.). The Oxford Handbook of Political Behavior. Oxford, Oxford University Press, 2007. p. 223-239.

INGLEHART, R.; WELZEL, C. Modernização, mudança cultural e democracia. São Paulo: Verbena, 2009.

KINZO, M. D. G. Radiografia do quadro partidário brasileiro. São Paulo: Fundação Konrad Adenauer-Stiftung, 1993.

KRAUSE, S. Coligacões: o estado e os desafios da arte. In: KRAUSE, S.; DANTAS, H.; MIGUEL, L. F. (Org.). Coligações partidárias na nova democracia brasileira. Rio de Janeiro: Konrad Adenauer Stiftung; São Paulo: UNESP, 2010. p. 9-21.

LANDIS, J. R.; KOCH, G. G. The Measurement of Observer Agreement for Categorical Data. Biometrics, Washington, v. 33, n. 1, p. 159-174, 1977.

LAVER, M.; BUDGE, I. Party policy and government coalitions. New York: St. Martin's Press, 1992.

LIMONGI, F.; CORTEZ, R. As eleições de 2010 e o quadro partidário. Novos Estudos CEBRAP, São Paulo, n. 88, p.2137, 2010.

LIPSET, S. Some Social Requisites of Democracy: Economic Development and Political Legitimacy. American Political f Science Review, Baltimore, v. 53, n1, p. 69-105, 1959.

N LÓPEZ, M. Á; MIRANDA, N; VALENZUELA-GUTIÉRRE,

\& P. A. Estimando el espacio politico del cono sur y Brasil: $\$$ las elecciones presidenciales en el eje izquierda-derecha. PostData, Buenos Aires, v. 18, n. 2, p. 403-442, 2013.

$\sum$ MADEIRA, R.; TAROUCO, G. Esquerda e Direita no Brasil: $\Re$ uma análise conceitual. Revista Pós Ciências Sociais, São సิ Luís, v. 8, n. 15, p. 171-185, 2011.

命 MADEIRA, R.; TAROUCO, G. Como partidos significam $\dot{i}$ e legitimam suas origens? Saliency Theory e análise dos textos partidários. In: ENCONTRO DA ASSOCIAÇÃO ¿ BRASILEIRA DE CIÊNCIA POLÍTICA , 8., 2102, Gramado. ¿ Anais... Gramado: ABCP, 2012.

MELO, C. R. The 2014 elections and the Brazilian party system. Brazilian Political Science Review, [S.l.], v. 9, n. 1, p. $93-114,2015$.

MELO, C. R.; CAMARA, R. Estrutura da competição pela Presidência e consolidação do sistema partidário no Brasil. Dados, Rio de Janeiro, v.55, n.1, p. 71-117, 2012.

MIGUEL, L. F. Os partidos brasileiros e o eixo"esquerdadireita”. In: KRAUSE, S.; DANTAS, H.; MIGUEL, L. F. (Org.). Coligações partidárias na nova democracia brasileira: perfis e tendências. Rio de Janeiro: Konrad Adenauer, 2010. p. 31-38.

MUSA, A. Was There a Silent Revolution? A Comparative Analysis of Party Manifestos in Ten European Countries. Politička misao, [S.l.], n. 43, n. 5, p. 121-146, 2006.

PARTIDO DA SOCIAL DEMOCRACIA BRASILEIRA. Programa de Governo José Serra: Uma Agenda para o Desenvolvimento Sustentável do Brasil. 2010. Disponível em: <http://www.psdb.org.br/programa-de-governo-docandidato-jose-serra/> . Acesso em: 7 dez. 2012.

POWER, T. Fernando Henrique e a "Terceira Via": Blairismo à Brasileira? In: TAVARES, J. A. G. (Org.). $O$ que esperar da Social-democracia no Brasil? Brasília, DF: Instituto Teotônio Vilela, p. 221-273, 2003.

POWER, T.;ZUCCO, C. Estimating Ideology of Brazilian Legislative Parties, 1990-2005. Latin American Research Review, Baltimore, v. 44, n. 1, p. 218-246, 2009.

PRZEWORSKI, A. et al. Democracy and Development: Political Institutions and Well-Being in the World, 19501990. Cambridge: Cambridge University Press, 2000.

ROBERTSON, D. B. A theory of party competition. London: Wiley, 1976.

SAMUELS, D. Determinantes do voto partidário em sistemas eleitorais centrados no candidato: evidências sobre o Brasil. Dados, Rio de Janeiro, v. 40, n. 3, p. 493$535,1997$.

SAMUELS, D.; ZUCCO, C. The power of partisanship in Brazil: Evidence from survey experiments. American Journal of Political Science, v. 58, n. 1, p. 212-225, 2014.

TAROUCO, G. Brazilian Parties According to their Manifestos: Political Identity and Programmatic Emphases. Brazilian Political Science Review, New York, v. 5, n. 1, p. 54-76, 2011.

TAROUCO, G, e MADEIRA, R. Esquerda e direita no sistema partidário brasileiro: análise de conteúdo de documentos programáticos. Debates, Porto Alegre, n. 7, n. 2, p. 93-114, 2013

TAROUCO, G.; MADEIRA. R. Os partidos brasileiros segundo seus estudiosos: Análise de um expert survey. Civitas, Porto Alegre, v. 15, n. 1, p. 24-39, 2015.

TAVARES, J. A. G. (Org). O que esperar da Socialdemocracia no Brasil? Brasília, DF: Instituto Teotônio Vilela, 2003

VIEIRA, S. M. O Partido da Social Democracia Brasileira: trajetória e ideolgia (1987-2010). Curitiba: CRV, 2016.

VOLKENS, A. et al.. Manifesto Project. Berlin: Wissenschaftszentrum Berlin für Sozialforschung, 2013. Disponivel em: < https://manifesto-project.wzb.eu/ $>$. Acesso em: 16 maio 2013. 


\section{AGENDAS, PREFERENCES, COMPETITION: PT and PSDB in presidential disputes}

\author{
Rafael Madeira \\ Soraia Vieira \\ Gabriela Tarouco
}

In the Brazilian political science, there is a debate about the bipolarization of the party system resulting from the concentration of the competition in the presidential elections in two parties: PT and PSDB. This article aims to identify the content and the terms of competition among such parties concerning their thematic emphasis by comparing government plans of each party for the presidential elections from 2006 to 2014. The hypothesis, derived from saliency theory, is that the competition between them is based on the selection of specific themes and alternative agendas. The method used to measure agendas and preferences is the content analysis, applying the categories of the Manifest Research Group - MARPOR. The results reveled that platforms come closer to each other due to the inclusion of themes of the national public agenda, but they are distinguished in the priorities that each party establish and in the direction in which they adapt their emphases over time.

KEYwORDS: Manifests; content analysis; political parties; presidential elections; public policy agenda.

\section{AGENDAS, PRÉFÉRENCES, COMPÉTITION: PT et PSDB se disputent les présidentielles}

\author{
Rafael Madeira \\ Soraia Vieira \\ Gabriela Tarouco
}

$\mathrm{Au}$ sein de la science politique brésilienne et en ce qui concerne les élections présidentielles, il existe un débat sur la bipolarisation du système des partis résultant d'une concentration de la compétition autour de deux partis, le PT et le PSDB. Cet article se veut d'identifier le contenu et les termes de la concurrence entre ces partis en fonction de leurs axes thématiques et de comparer leurs programmes gouvernementaux respectifs lors des élections présidentielles de 2006 à 2014. L'hypothèse, dérivée de la saliency theory, est que la compétition qui s'engage entre eux est basée sur la sélection de thèmes spécifiques et de compromis alternatifs. La méthode utilisée pour mesurer les compromis et les préférences est l'analyse de contenu à laquelle on applique les catégories du Manifest Research Group - MARPOR. Les résultats révèlent que les plates-formes se rapprochent par l'inclusion de thèmes des compromis publics nationaux, mais se distinguent au niveau des priorités établies et de la direction prise pour adapter leurs efforts au fil du temps.

Mots-ClÉs: Manifestes. Analyse de contenu. Partis politiques. Élections présidentielles. Compromis des politiques publiques.

Rafael Madeira - Doutor em Ciência Política pelo PPGCP da UFRGS. Professor adjunto do PPG em Ciências Sociais da Pontifícia Universidade Católica do Rio Grande do Sul (PUCRS). Publicações recentes: Os partidos brasileiros segundo seus estudiosos: análise de um expert survey. Civitas, Porto Alegre, v. 15, n. 1, p. e24-e39, 2015. Em coautoria com Gabriela Tarouco; Partidos, programas e o debate sobre esquerda e direita no Brasil. Revista de Sociologia e Política (UFPR. Impresso), v. 21, p. 149-165, 2013. Em coautoria com Gabriela Tarouco.

Soraia Vieira - Doutora em Ciência Política pelo Instituto de Ciências Sociais e Políticos da UERJ. Professora adjunta na Universidade Federal Fuminense. Publicação recentes: O partido da Social Democracia Brasileira Trajetória e ideologia (1987-2010). Curitiba: CRV, 2016.

Gabriela Tarouco - Doutora em Ciência Política pelo IUPERJ. Professora adjunta na Universidade Federal de Pernambuco. Publicação recente: The role of political parties in electoral governance: delegation and the quality of elections in Latin America. Election Law Journal, v. 15, p. 83-95, 2016. 
